\title{
Fission yeast genes involved in coupling mitosis to completion of DNA replication
}

\author{
Tamar Enoch, ${ }^{1,3,4}$ Anthony M. Carr, ${ }^{2}$ and Paul Nurse ${ }^{1}$ \\ ${ }^{1}$ Imperial Cancer Research Fund Cell Cycle Group, Microbiology Unit, Department of Biochemistry, Oxford University, \\ Oxford OX1 3QU UK; ${ }^{2}$ Medical Research Council Cell Mutation Unit, Sussex University, Falmer, E. Sussex, BN1 9RR UK
}

\begin{abstract}
We have isolated fission yeast mutants that enter mitosis when DNA replication is blocked with hydroxyurea. The mutants define eight linkage groups, three of which consist of alleles of the rad1, rad3, and rad17 genes. Recently, these fission yeast genes have been shown to be required for radiation-induced cell cycle arrest, as is the budding yeast $R A D 9$ gene. The other five genes are called hus (hydroxyurea sensitive) 1-5. We propose that these genes participate in an intracellular signal transduction pathway that monitors the completion of DNA replication and transmits information to the mitotic control protein cdc2. Mutations that bypass the requirement for $c d c 25$ (an activator of the mitotic regulator cdc2) also uncouple mitosis from DNA replication. However, mitosis is blocked by inhibitors of DNA replication in strains in which the cdc25 gene has been deleted, indicating that although cdc25 influences the coupling of mitosis to the completion of DNA replication, it is not essential for this control.
\end{abstract}

[Key Words: Cell cycle; checkpoint; radiation; cdc25; S. pombe]

Received May 4, 1992; revised version accepted August 27, 1992.

A normal cell cycle consists of a temporally ordered series of events. This order is maintained partly by mechanisms that can monitor completion of earlier events, called "checkpoint" (Hartwell and Weinert 1989) or "feedback" (Murray and Kirschner 1989) controls. Elimination of such controls by mutation or chemical treatment disrupts the dependencies characteristic of ordered progression through the cell cycle (for review, see Hartwell and Weinert 1989). Although mutations that abolish several different cell cycle checkpoints have been identified (Weinert and Hartwell 1988; Hoyt et al. 1991; $\mathrm{Li}$ and Murray 1991), it is not clear how these controls work. Early steps must "signal" late steps, but little is known about what these signals are or how they are monitored.

We are investigating this problem by studying the coupling of mitosis to the completion of DNA replication in the fission yeast Schizosaccharomyces pombe. This system is attractive because the control of mitosis has been studied extensively using genetic, biochemical, and molecular techniques (for review, see Forsburg and Nurse 1991). Initiation of mitosis requires activation of a protein kinase encoded by the gene $c d c 2$. Proteins homologous to cdc2, in conjunction with conserved proteins called cyclins, are required for the initiation of mitosis in all eukaryotic cells (for review, see Nurse 1990; Maller 1990).

In fission yeast, dominant $c d c 2$ mutants that advance mitosis have been identified, demonstrating that cdc2

\footnotetext{
${ }^{3}$ Corresponding author.

${ }^{4}$ Present address: Department of Genetics, Harvard Medical School, Boston, Massachusetts 02115 USA.
}

controls the timing of mitosis as well as playing a role in its initiation (for review, see Forsburg and Nurse 1991). We have shown that one of these mutations, $c d c 2-3 w$ (Fantes 1981), abolishes the checkpoint coupling mitosis to DNA replication (Enoch and Nurse 1990). Although the $c d c 2-3 w$ mutation leads to advancement of mitosis, this alone cannot explain loss of checkpoint control, as other mutations with equal or greater effects on the length of $\mathrm{G}_{2}$ (e.g., wee1-50 and $c d c 2-1 w$ ) do not abolish the dependence of mitosis on completion of DNA replication. This suggests that timing controls and checkpoint controls are distinct, although some of the same elements are involved in both.

cdc2 kinase activation in fission yeast is regulated by phosphorylation of a tyrosine residue in the ATP-binding site (Gould and Nurse 1989). Phosphorylation of this tyrosine is also required for detection of unreplicated DNA, as mutation of the tyrosine to phenylalanine abolishes checkpoint control (Enoch et al. 1991; Sorger and Murray 1992). Tyrosine phosphorylation of cdc2 couples mitosis to completion of DNA replication in other eukaryotic systems (for review, see Enoch and Nurse 1991), although it does not appear to be important in budding yeast (Amon et al. 1992; Sorger and Murray 1992). This may be because DNA synthesis and spindle formation proceed simultaneously in budding yeast (Byers 1981; Li and Murray 1991), whereas in fission yeast and many other eukaryotes, spindle formation marks the onset of mitosis and is separated temporally from DNA synthesis by a $\mathrm{G}_{2}$ period. Thus, in the budding yeast cell cycle, the completion of mitosis is dependent on DNA replication. In contrast, in the fission yeast cell cycle, initiation of 
mitosis is dependent on the completion of DNA replication. This may explain why the mutation of the $\mathrm{cdc} 2$ tyrosine residue, which severely disrupts cell cycle control in fission yeast (Gould and Nurse 1989) and in cultured chick cells (Krek and Nigg 1991), has no effect on the budding yeast cell cycle (Amon et al. 1992; Sorger and Murray 1992).

The level of fission yeast cdc2 tyrosine phosphorylation is determined by a balance between the activities of a tyrosine phosphatase, encoded by the fission yeast cdc25 gene (for review, see Millar and Russell 1992), and tyrosine kinases, encoded by the wee 1 and mik 1 genes (Featherstone and Russell 1991; Lundgren et al. 1991). In previous studies we have shown that overexpression of cdc25 results in a decrease in tyrosine-phosphorylated cdc2 and abolishes checkpoint control. In contrast, advancing the cell cycle by eliminating wee1 has a much less pronounced effect on the levels of tyrosine-phosphorylated cdc2, and no effect on checkpoint control (Enoch and Nurse 1990; Enoch et al. 1991). On the basis of these data, we have previously proposed that the $c d c 25$ gene products play a direct role in monitoring the completion of DNA replication and that wee1 plays no role in this control (Enoch and Nurse 1990).

To understand how incomplete DNA replication is detected by $\operatorname{cdc} 2$ we have developed a screen for fission yeast mutants that initiates mitosis when DNA replication is blocked using hydroxyurea (HU). We call this the hus phenotype, for hydroxyurea sensitive, as the mutations are abnormally sensitive to HU. The mutations that we have identified define eight different linkage groups, three of which consist of alleles of the previously identified genes rad1, rad3, and rad17. The other five linkage groups define apparently new genes, which we are designating hus1-hus5. Mutations in the three rad genes were initially isolated on the basis of their sensitivity to ionizing and UV radiation (Phipps et al. 1985). Recently, these genes have been shown to be required for radiation-induced cell cycle arrest in $G_{2}$, as is the budding yeast $R A D 9$ gene (Al-Khodairy and Carr 1992; Rowley et al. 1992a). The new hus mutants are also radiation sensitive, demonstrating that cell cycle arrest in response to blocked DNA replication and DNA damage requires many of the same elements. The rad mutants and some of the hus mutants were found to be significantly more sensitive to $\mathrm{HU}$ than $c d c 2-3 w$, although they are equally deficient in checkpoint control. We present evidence suggesting that hus and rad mutants are also deficient in a second function, possibly recovery from S-phase arrest.

We have also re-examined the roles of the wee1 and cdc25 gene products in coupling mitosis to completion of DNA replication. We find that strains lacking both gene products can still respond to unreplicated DNA, indicating that neither protein is essential for checkpoint control. We also find that overexpression of wee1 can rescue the checkpoint deficiency of $c d c 2-3 w$ cells, showing that wee1 can influence the response to unreplicated DNA, even though it is not required. We consider models consistent with these observations.

\section{Results}

Isolation of hus mutants

We have shown previously that $c d c 2-3 w$ is deficient in the checkpoint that links mitosis to the completion of DNA replication (Enoch and Nurse 1990). As a result, cells die after short exposures to HU. Such cells are septated, and the septum either cleaves the single nucleus or divides the cell such that one daughter is anucleate. Typical mitotic spindles can be detected in these cells before septum formation, although there in no nuclear division (Enoch and Nurse 1990). This resembles the morphology of cut mutants, which undergo cytokinesis in the absence of chromosome segregation (Hirano et al. 1986); therefore, we refer to cells with this morphology as "cuts".

To identify additional fission yeast genes involved in coupling mitosis to completion of DNA replication, we developed a screen for mutants that enter mitosis in HU. Initially, we screened for colonies that were abnormally sensitive to HU by replica-plating cells onto plates with or without HU and picking clones that failed to form colonies on HU. Fifty thousand colonies from a nitrosoguanidine-mutagenized population were screened in this fashion, and 118 were chosen for further analysis (for experimental details, see Materials and methods). Each of these mutants was examined cytologically in liquid culture in the presence of HU. Twenty of these mutants entered mitosis with unreplicated DNA, as judged by the presence of $\geqslant 20 \%$ cuts (Fig. 1A-C,E,F; white arrows indicate septa).

Mapping studies showed that mutants fall into eight different linkage groups (Table 1). Three of these consist of alleles of previously identified rad genes: $\mathrm{rad} 1, \mathrm{rad} 3$, and $\mathrm{rad} 17$ (see below). The remaining five linkage groups identify new genes involved in coupling mitosis to the completion of DNA replication, which we are calling hus1-hus5. None of the mutants was advanced into mitosis in the absence of HU. This contrasts with the checkpoint deficiencies that we have described previously, all of which affect mitotic control elements and advance mitosis in untreated cultures (Enoch and Nurse 1990). Most of the mutants were indistinguishable from wild type in the absence of HU. However, two mutants, hus2-22 and hus5-17, had growth defects and were temperature sensitive. The defect in hus5-17 was severe $160 \%$ longer doubling time compared with wild type at $29^{\circ} \mathrm{C}$ l, whereas the defect in hus $2-22$ was only moderate $\left(28 \%\right.$ longer doubling time than wild type at $\left.29^{\circ} \mathrm{C}\right)$. Diploids heterozygous for each of the hus mutants and for representative alleles of rad1, rad3, and rad17 were constructed, and all were found to be recessive for HU sensitivity, except hus5-17, which was dominant for the hus but recessive for the temperature-sensitive phenotype.

Interaction of hus mutations with mitotic control genes cdc2, cdc25, and wee1

Previously, we have shown that mutation of $c d c 2$ or cdc25 can abolish checkpoint control and give rise to a 


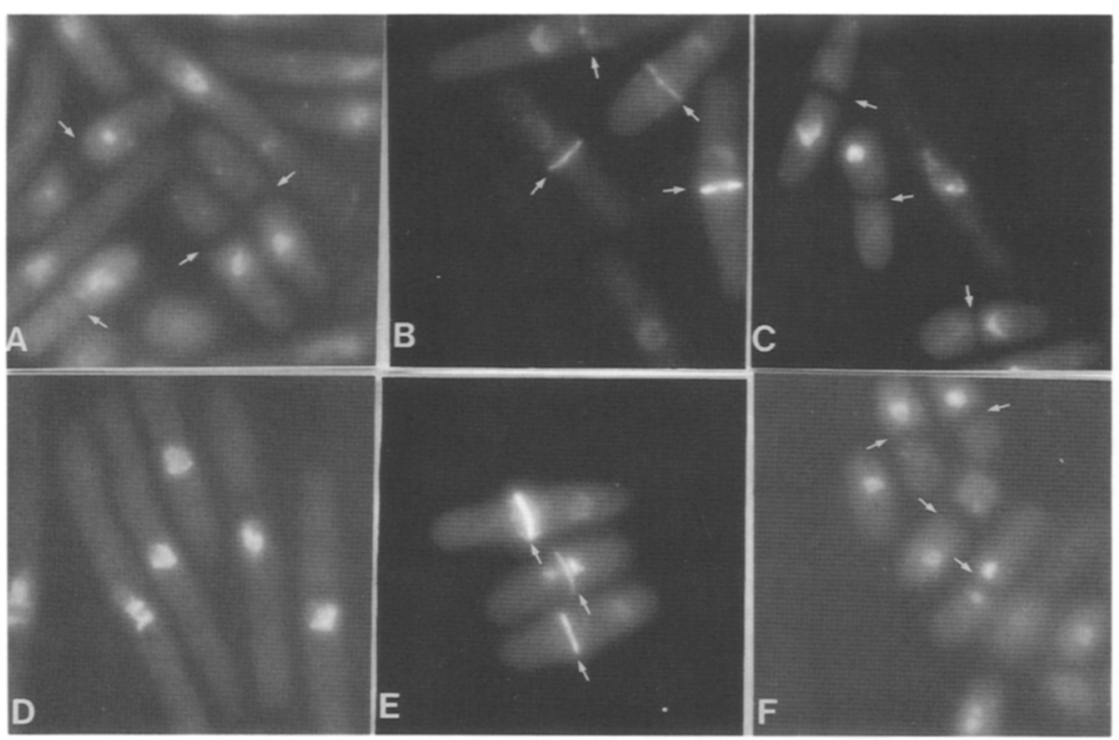

Figure 1. Fission yeast mutants that enter mitosis when DNA replication is blocked with HU. The indicated strains were incubated in $\mathrm{HU}$, fixed with ethanol and stained with the DNA-binding dye DAPI and calcofluor as described in Materials and methods. $(A)$ hus4-16; $(B)$ hus222; $(C)$ hus2-22; $(D)$ wild type; $(E)$ hus1-14; and $(F)$ hus1-14. Cells in $A, E, C$, and $F$ are stained with DAPI alone. Septa appear as unstained bars (arrows). Cells in $B$ and $E$ are stained with DAPI and calcofluor; septa (arrows) are brightly fluorescing and the nuclei stain more faintly. Note that wild type cells $(D)$ are elongated, have no septa, and contain a single DAPI-staining nuclear area. Many of the mutant cells are septated, and the septum either cuts the nucleus or divides the cell such that one daughter is anucleate. Anucleate cells and cells with abnormally low amounts of DAPI-staining material are also observed.

hus phenotype. Therefore, we tested all of the hus mutants for linkage with $c d c 2, c d c 25$, and wee1. None of the mutants was linked closely to $c d c 2$ or $c d c 25 \mid \geqslant 20 \%$ wild-type recombinants in 200 spores), and except for hus4-16, none was closely linked to wee1 $1 \geqslant 20 \%$ wildtype recombinants in 200 spores). The close linkage of hus 4 and wee1 (3\% recombinants in 1000 spores) could mean that hus 4-16 is an allele of wee1. However, we were able to construct a hus4-16 wee1-50 double mutant displaying both wee and hus phenotypes. Because the hus and wee phenotypes are different and both may be the result of loss of function, it seems likely that hus4 and wee1 are separate genes.

All of the mutants except hus4-16 displayed a lethal temperature-sensitive phenotype when a temperaturesensitive allele of wee1 (wee1-50) was introduced into the strain. The phenotype at the restrictive temperature was similar to the previously described "mitotic catastrophe" (Russell and Nurse 1986, 1987) characteristic of uncontrolled entry into mitosis (Fig. 2). In contrast to the other hus mutants, hus4-16 wee1-50 did not display a mitotic catastrophe phenotype at $36.5^{\circ} \mathrm{C}$, but this may be because the hus phenotype is suppressed at $36.5^{\circ} \mathrm{C}$ in hus4-16 (data not shown).

In addition to disrupting checkpoint control, the $c d c 2$ $3 w$ mutation also suppresses $G_{2}$ arrest due to mutation of $c d c 25$ (Fantes 1981) and partially suppresses $G_{2}$ arrest induced by overexpression of the mitotic inhibitor wee1 (Russell and Nurse 1987). However, overexpression of weel blocked cell division in all of the hus and rad mutants, indicating that these mutations, unlike $c d c 2-3 w$, do not interfere with weel function. In addition, hus cdc25-22 and hus cdc2-33 double mutants displayed both parental phenotypes, namely $\mathrm{HU}$ sensitivity at $25^{\circ} \mathrm{C}$ (the permissive temperature for $c d c$ mutants), and cell cycle arrest at $36.5^{\circ} \mathrm{C}$ /the restrictive temperature for $c d c$ mutants) and had no other unexpected characteris- tics, indicating that $c d c 25$ - and $c d c 2$-dependent controls are normal in these mutants.

\section{hus mutants are deficient in radiation response}

In most cells irradiation induces a cell cycle delay (for review, see Hartwell and Weinert 1989). The budding yeast $\mathrm{rad} 9$ mutant fails to delay cell division in response

Table 1. Genetic analysis of hus mutants

\begin{tabular}{|c|c|c|}
\hline Gene & Alleles & Comments \\
\hline hus1 & 14 & \\
\hline hus2 & 22 & $\begin{array}{l}28 \% \text { increase in doubling } \\
\text { time } \mathrm{e}^{\mathrm{a}}, 15 \% \text { recombination } \\
\text { with } c d c 25\end{array}$ \\
\hline hus3 & 12,26 & $\begin{array}{l}\text { both alleles suppressed in } \\
\text { minimal medium }\end{array}$ \\
\hline hus4 & 16 & $\begin{array}{l}\text { suppressed at } 36.5^{\circ} \mathrm{C} ; 3 \% \\
\text { recombination with wee1; } \\
\text { no synthetic lethality with } \\
\text { wee1-50 }\end{array}$ \\
\hline hus5 & 17 & $\begin{array}{l}60 \% \text { increase in doubling } \\
\text { time }^{a} \text {; dominant }\end{array}$ \\
\hline $\operatorname{rad1}$ & h24 & \\
\hline rad3 & $\begin{array}{l}h 4, h 5, h 6, h 10, \\
h 13, h 15, h 18, \\
h 19, h 20, h 23\end{array}$ & \\
\hline rad17 & $h 11, h 21$ & \\
\hline
\end{tabular}

${ }^{\mathrm{a} I n c r e a s e s}$ in doubling time are relative to wild type at $29^{\circ} \mathrm{C}$. Summary of genetic analysis of 20 hus mutants isolated from a mutagenized population of 50,000 cells. The mutants define eight linkage groups. Six of the mutations define five new genes, called hus genes. In addition, 1 allele of rad1, 10 alleles of rad3, and 2 alleles of rad17 were isolated. The hus mutations are unlinked to $c d c 2, c d c 25$, and, with the exception of hus4-16, wee1. All of the hus mutations are recessive except for hus5-17 (for details, see text). 


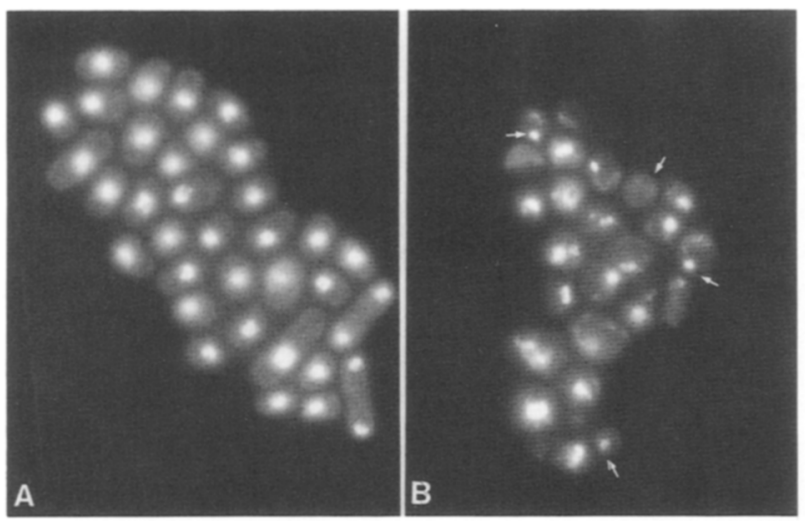

Figure 2. hus mutants are lethal in combination with a deficiency in the mitotic inhibitor wee1. hus wee1-50 double mutants were constructed using standard genetic techniques. wee 1-50 is a temperature-sensitive allele of wee1. When hus wee $1-50$ mutants were incubated at $36.5^{\circ} \mathrm{C}$ (the restrictive temperature for wee1-50), the cells died exhibiting features characteristic of a mitotic catastrophe (see Russell and Nurse 1986). A typical result is shown here. $(A)$ hus3-12 wee1-50 at $25^{\circ} \mathrm{C} ;(B)$ hus $3-12$ wee $1-50$ at $36^{\circ} \mathrm{C}$. Cells were stained as in Fig. 1. Examples of anucleate cells and cells containing abnormally low amounts of DNA are indicated by arrows.

to radiation, indicating that $R A D 9$ is a component of a checkpoint that blocks mitosis when DNA is damaged (Weinert and Hartwell 1988). Recently, the fission yeast mutants rad1 (Al-Khodairy and Carr 1992; Rowley et al. 1992a), rad3, rad9, and rad17 (Al-Khodairy and Carr 1992) were shown to be deficient in this checkpoint. Like the hus mutants, these mutants also enter mitosis when DNA synthesis is blocked with HU (Al-Khodairy and Carr 1992; Rowley et al. 1992a). Therefore, we tested the hus mutants for linkage to these four rad genes. $\mathrm{Mu}$ tants in three of the eight linkage groups were found to be alleles of rad1, rad3, or rad17, as shown in Table 1 (no wild type recombinants in 200 spores). To investigate further the relationship between radiation and HU-induced inhibition of mitosis, we tested each of the hus mutants for sensitivity to UV irradiation. rad17-h11 and hus1-14 were more sensitive than wild type to low 150 $\mathrm{J} / \mathrm{m}^{2}$ ) doses of UV radiation (Fig. 3, stippled boxes; note log scale). All of the mutants were more sensitive than wild type to higher doses $\left(300 \mathrm{~J} / \mathrm{m}^{2}\right)$ of radiation (Fig. 3, solid boxes; note log scale). This confirms and extends previous studies suggesting that inhibition of mitosis by unreplicated DNA and by radiation-damaged DNA in fission yeast involves many common elements (AlKhodairy and Carr 1992; Rowley et al. 1992a).

\section{Characterization of the checkpoint deficiency in hus and rad mutants}

Studies with synchronous cultures have shown that in $c d c 2-3 w$ cells the length of the cell cycle is the same whether or not DNA replication is inhibited, indicating that mitosis is completely uncoupled from DNA repli- cation (Enoch and Nurse 1990). To assess the severity of the checkpoint deficiency in our new mutants, we examined the rate of mitosis in the absence of DNA replication by following the kinetics of cut formation in asynchronous cultures after the addition of $\mathrm{HU}$. All of the hus mutants and representative alleles of each of the rad genes were examined in this manner (for experimental details, see Materials and methods). On the basis of these studies, the mutants could be divided into categories, as summarized in Table 2. The first category consisted of cells that enter mitosis with the same kinetics as $c d c 2$ $3 w$. Five of the mutants (hus1-14, hus2-22, rad1-h24, rad3-h1, and rad17-h11) were in this category; significant levels of cut cells could be detected when these strains were cultured in HU for $4 \mathrm{hr}$ (Table 2 and Fig. 4). This suggests that the defect in mitotic control in these strains is quantitatively similar to that described for $c d c 2-3 w$ (Enoch and Nurse 1990). We refer to this as the "early cut" category of mutants.

The second category of mutants, which are called "late cut," entered mitosis but with a delay in kinetics. In these strains, inhibition of DNA replication must delay, although not block, mitosis. This could be the result of quantitative or qualitative differences in the checkpoint deficiency compared with the early cut mutants. Three of the mutants, hus3-12, hus3-26, and hus4-16 showed this phenotype (Table 2). The extent of cut formation in both alleles of hus 3 was influenced by the medium; in minimal medium, cut formation could be suppressed almost completely (for hus3-26, see Table 2; similar data not shown for hus3-12).

One mutant, hus5-17 fell into the third category, "constant cut," displaying a low (15\%) level of cuts in untreated cultures; and this percentage remained constant during $\mathrm{HU}$ incubation (Table 2; data not shown). This contrasts with the behavior of the rest of the mutants,

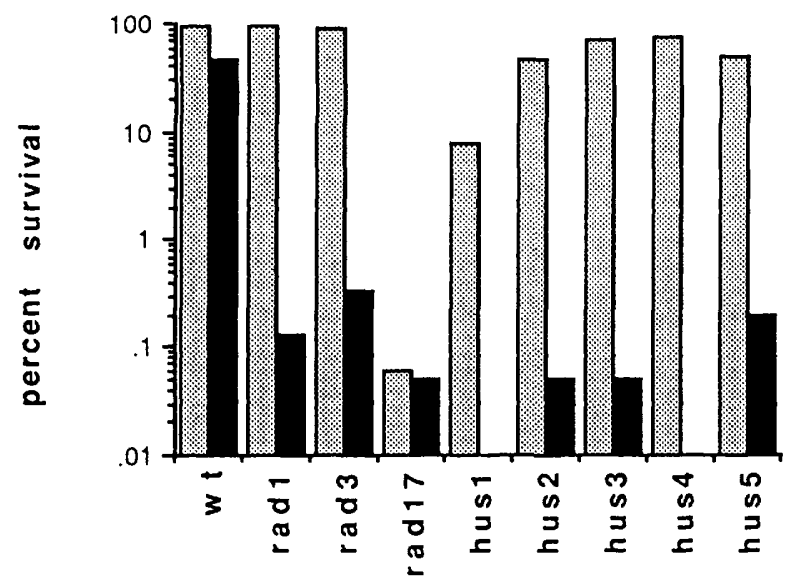

Figure 3. Radiation sensitivity of hus mutants. Wild type and hus mutants were irradiated with either $50 \mathrm{~J} / \mathrm{m}^{2}$ (stippled bars) or $500 \mathrm{~J} / \mathrm{m}^{2}$ (solid bars) of UV light, and percent survival relative to unirradiated controls was determined. Mutants are indicated beneath the bars. Alleles are rad1-h24, rad17-h11, rad3-136, hus1-14, hus2-22, hus3-26, hus4-16, and hus5-17. 
Table 2. Response of mutants to $H U$

\begin{tabular}{llrrc}
\hline & Category & $\begin{array}{l}\text { Percent } \\
\text { cut } \\
(4 \mathrm{hr})\end{array}$ & $\begin{array}{l}\text { Percent } \\
\text { cut } \\
(6 \mathrm{hr})\end{array}$ & $\begin{array}{l}\text { Percent } \\
\text { viability } \\
(6 \mathrm{hr})\end{array}$ \\
\hline Wilrain & wild type & 0 & 0 & $150^{\mathrm{a}}$ \\
cdc2-3w & early cut & 51 & 62 & 28 \\
hus1-14 & early cut & 58 & 59 & 1 \\
hus2-22 & early cut & 38 & 58 & 0.03 \\
rad1-h24 & early cut & 66 & 73 & 1.5 \\
rad3-h1 & early cut & 57 & 51 & 1.1 \\
rad17-h11 & early cut & 54 & 58 & 2 \\
hus3-26 & & & & \\
$\quad$ rich medium & late cut & 9 & 47 & 47 \\
min. medium & wild type & 0 & 3 & $150^{\mathrm{a}}$ \\
hus4-16 & late cut & 3 & 17 & 1 \\
hus5-17 & constant cut & 17 & 15 & 26 \\
\hline
\end{tabular}

The number of viable cells is $>100 \%$ because cells that are in $\mathrm{G}_{2}$ at the time of $\mathrm{HU}$ addition divide before arresting.

Classification of mutants according to the effects of $\mathrm{HU}$ on the length of the cell cycle. Viability and entry into mitosis in the absence of DNA replication (as determined by cut formation) were monitored in mutant cells incubated in HU for 4 and $6 \mathrm{hr}$. On the basis of the kinetics of entry into mitosis, mutants were classified as early, late, or constant cut. Unless noted otherwise, all incubations were carried out in minimal media. The early and late cut mutants showed no cuts at the start of the experiments; the constant cut mutant hus $5-17$ had $15 \%$ cuts (data not shown).

and the physiology of this strain needs to be explored further before it can be concluded that the deficiency directly affects checkpoint control. However, as it shares important phenotypes with the other checkpoint mutants (radiation sensitivity, lethality with weel), it probably warrants further study.

\section{Early-cut mutants are much less viable in $\mathrm{HU}$} than cdc2-3w cells

Because early-cut mutants disrupted the checkpoint control to the most significant extent, they were chosen for more detailed analysis. $c d c 2-3 w$ cells lose viability with incubation in HU because mitosis is initiated in the absence of DNA replication (Enoch and Nurse 1990). Earlycut mutants also lose viability in HU, but in most cases to a surprisingly greater extent. As shown in Table 2, after 6 hours of incubation in HU, 15- to 100-fold fewer cells survive compared with $c d c 2-3 w$. Viability is also significantly reduced in hus $4-16$, one of the late-cut mutants. To understand the basis of this difference, we compared loss of viability, arrest in $G_{1}$ and entry into mitosis in the absence of DNA replication as judged by cuts in cultures of $c d c 2-3 w$ and in three early-cut mutants, rad1-h24, rad3-h1, and hus1-14. Data for hus1-14 is shown in Figure 4. Less than $0.1 \%$ of the hus $1-14$ cells survive treatment with $\mathrm{HU}$ compared with $15 \%$ of the cdc2-3w cells (Fig. 4A; note log scale). The higher viability of the $c d c 2-3 w$ culture cannot be the result of a more efficient checkpoint as both strains enter mitosis, as judged by cut formation, with the same kinetics and to the same extent (Fig. 4B). DNA synthesis was inhibited to the same extent in both strains, as determined by the percentage of cells in $G_{1}$ (Fig. 4 C). Similar results were obtained with rad1-h24 and rad3-h15 (not shown). These results suggest that early-cut mutants may have an additional deficiency in the cellular response to inhibition of DNA replication.

We noticed that hus1-14 and $c d c 2-3 w$ also lose viabil-

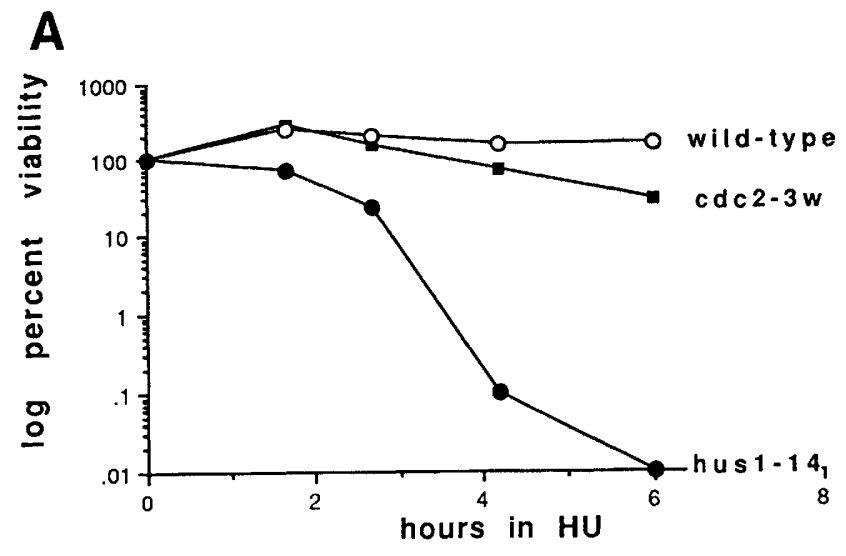

B
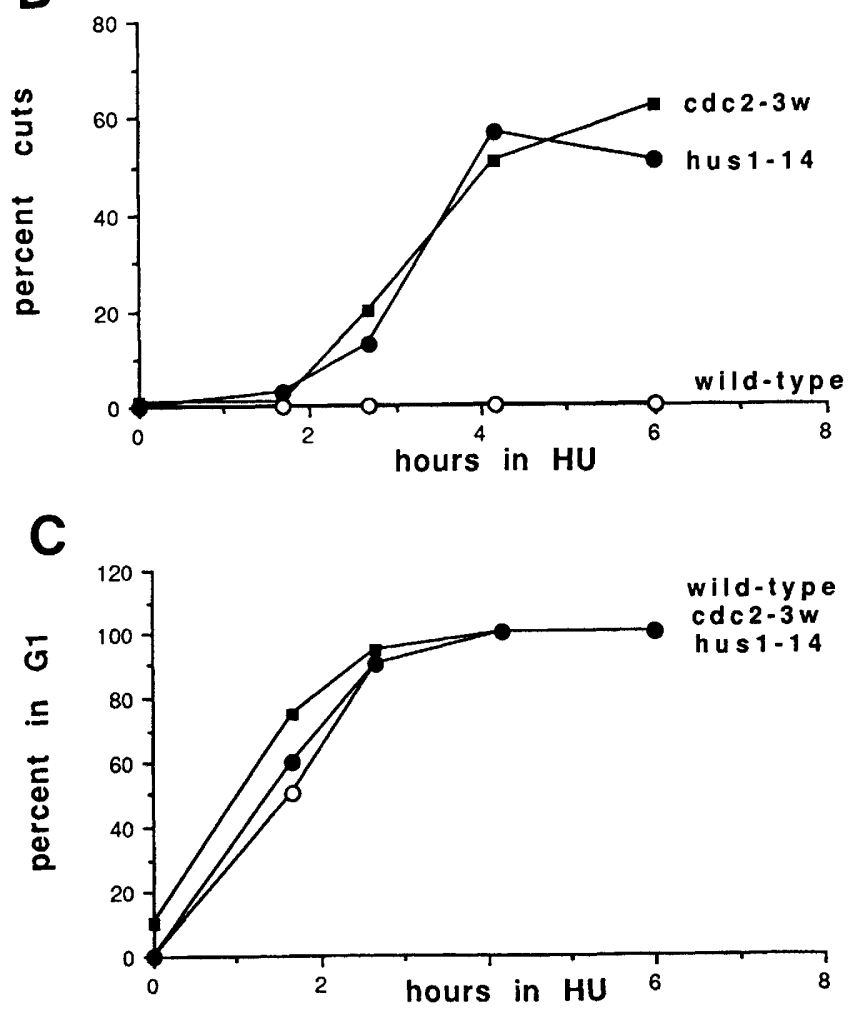

Figure 4. Comparison of response of wild type, $c d c 2-3 w$, and hus 1-14 cells to HU. All three strains were incubated in HU, and samples were plated for viability $|A|$, fixed and examined for cuts $(B)$, or fixed and the fraction of the population in $\mathrm{G}_{1}$ was determined using FACS analysis $(C)$ at the indicated times $(\mathrm{hr})$. (O) Wild type; (O) hus1-14; (D) cdc2-3w. 
ity with different kinetics. As shown in Figure 4A, after $21 / 2 \mathrm{hr}$, hus $1-14$ cultures have $40 \%$ fewer viable cells than wild type (note log scale). In contrast, $c d c 2-3 w$ and wild type cultures have the same proportion of viable cells at this time. The proportion of viable cells in $c d c 2$ $3 w$ does not differ significantly from wild type until $4 \mathrm{hr}$ (Fig. 4A). Because we have shown previously that loss of viability in $\mathrm{HU}$ in $c d c 2-3 w$ correlates with initiation of mitosis, this suggested that the hus1 gene might be required at an earlier point in the cell cycle. To determine whether this was the case, we investigated loss of viability in synchronous cultures of both strains incubated in $\mathrm{HU}$ (Fig. 5). Cells in the early part of $\mathrm{G}_{2}$ were collected using an elutriator rotor and inoculated into fresh media. $\mathrm{HU}$ was added to half the culture $1 \mathrm{hr}$ later, and viability and septation were measured in both cultures every 20 min. Because we added HU to the cells when they were in $\mathrm{G}_{2}$, they underwent one normal round of division. The $\mathrm{S}$ phase of the next cell cycle was blocked in the cultures treated with HU, but in both strains the HU-treated cells still underwent a second round of cell division, with the same (or in the case of hus1-14, slightly faster) kinetics as untreated cultures (data for untreated cultures not shown). This second division in the HU-treated culture resulted in the formation of cuts as mitotic events occurred in the absence of DNA replication. Because the timing of mitosis in both hus1-14 and $c d c 2-3 w$ is not significantly delayed by inhibition of DNA replication, we conclude that both strains are completely deficient in the control coupling of mitosis to the completion of DNA replication.

As shown previously (Enoch and Nurse 1990), cdc2-3w cells lose viability just before they form cuts during the second round of cell division (Fig. 5A). In contrast, hus114 cells lose viability significantly earlier, just after the cells complete the normal division (Fig. 5B). Previous experiments with synchronous cultures have established that this is the time when S phase would normally be in progress (Nurse 1975). This suggests that hus1-14 lacks a function that is absolutely required early in the cell cycle when DNA replication is inhibited, in addition to being deficient in the coupling of mitosis to the completion of DNA replication. A likely explanation is that the hus1 gene product is required for recovery from S-phase arrest (see Discussion). This may explain why hus1-14 cells lose viability to a greater extent than $c d c 2-3 w$ cells, although the two strains are equally deficient in checkpoint control. Although all of the cells in both $c d c 2-3 w$ and hus 1-14 cultures cut, this alone may not always be lethal as $\sim 20 \%$ of the time the septum misses the nucleus entirely, resulting in one viable daughter. In contrast, as DNA synthesis is inhibited in $100 \%$ of the cells, a defect in a recovery function would be expected to affect every cell in the population, even those that survive the cut.

As the other early-cut mutants lose viability to the same extent as hus1-14 (Table 2) and with the same kinetics in asynchronous cultures (data not shown), they are also likely to be deficient in both the recovery function and the checkpoint control.

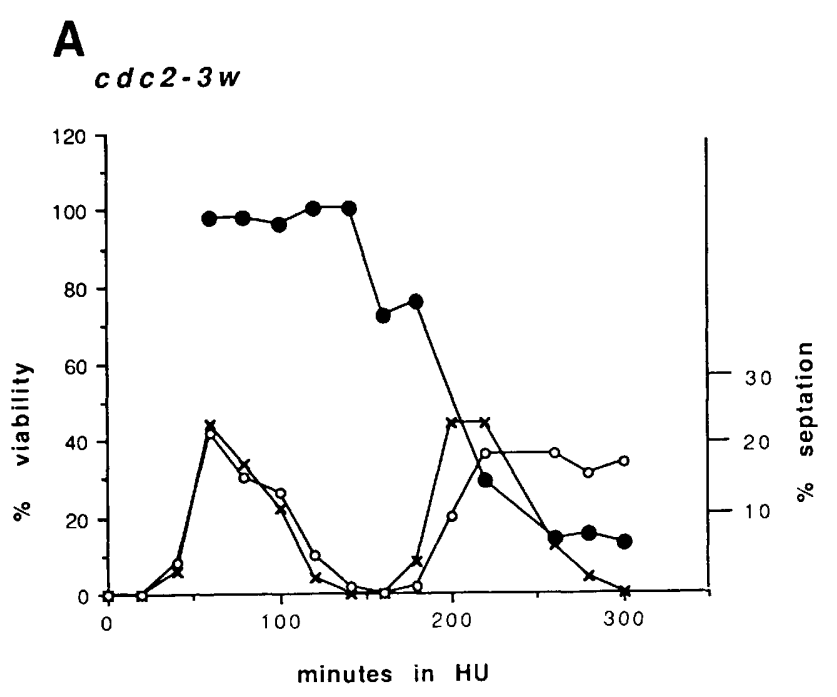

B

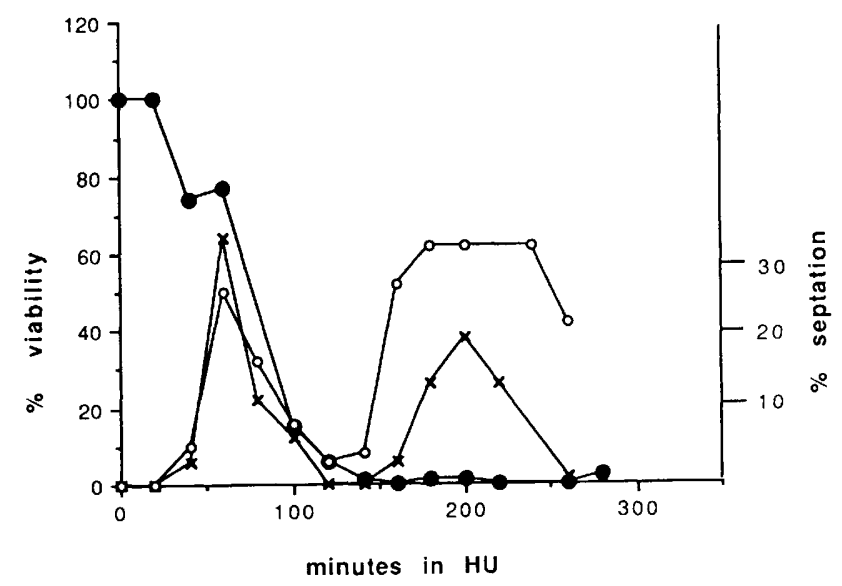

Figure 5. HU-treated $c d c 2-3 w$ and hus1-14 cells lack functions required at different times in the cell cycle. $\mathrm{G}_{2}$ cells from $c d c 2$ $3 W(A)$ and hus 1-14 $(B)$ were prepared by synchronizing cells by centrifugal elutriation and incubating them for $\mathrm{l} \mathrm{hr}$ to allow recovery from elutriation and completion of $S$ phase. At this point, the culture was split and HU was added to half of the cells. Samples from treated and untreated cultures were monitored for septation, and HU-treated cells were plated for viability. $(X)$ Percent septation in control cultures; $(O)$ percent septation in HU-treated cultures; $(0)$ percent viability in HUtreated cultures. Because the cells were in $G_{2}$ when the $H U$ was added, they initially divided normally (peak 1) and then formed cuts as they entered mitosis with unreplicated DNA (peak 2). As shown previously $c d c 2-3 w$ cells lose viability as they cut $(A)$. In contrast, hus 1-14 cells die much earlier in the cell cycle $|B|$. The second division in HU-treated hus 1-14 cells was advanced by 20 min compared with the wild type controls in this experiment.

\section{Coupling of mitosis to the completion of DNA} replication in the absence of both cdc 25 and weel

The above experiments (Fig. 5) suggest that the hus1, hus 2 and rad1, rad3, and rad17 gene products act before cdc2 in the checkpoint pathway. An important problem 
is to identify elements that link these events with control of activation of the cdc2 kinase.

We have shown previously that mitosis is uncoupled from the completion of DNA replication when cdc25 control is bypassed. On the basis of these experiments, we proposed that the $c d c 25$ gene product couples activation of $\operatorname{cdc} 2$ to the completion of DNA replication (Enoch and Nurse 1990). For example, products of the hus and rad genes could be involved in inhibiting $c d c 25$ expression or activity when DNA replication is blocked. If this is the case, strains lacking $c d c 25$ should be deficient in the checkpoint. Although deletion of the $c d c 25$ gene is normally lethal, this can be suppressed by either the $c d c 2-3 w$ mutation or by mutation of wee1 (Fantes 1979,1981 ). We have shown previously that the strains $\Delta \operatorname{cdc} 25 c d c 2-3 W$ and $\Delta \operatorname{cdc} 25$ wee1-50 differ in their response to HU (Enoch et al. 1991). To see whether this was the result of differences in checkpoint control, both strains were incubated in media containing $\mathrm{HU}$, and viability and cut formation were monitored. As expected, $\Delta c d c 25 c d c 2-3 w$ cells entered mitosis in the absence of DNA replication, as judged by the loss of viability (Fig. $6 \mathrm{C}$ ) and formation of cuts (Fig. 6B, D). In contrast, the $\Delta \mathrm{cdc} 25$ wee1-50 strain remained viable in $\mathrm{HU}$ (Fig. 6C) and showed a typical cell cycle arrest morphology (Fig. $6 \mathrm{~A}, \mathrm{D} \mid$. Thus, in cells lacking $c d c 25$ and wee1 mitosis is still dependent on the completion of DNA replication, indicating that neither gene is essential for coupling the activation of the cdc2 kinase to the completion of DNA replication.

\section{Overexpression of weel restores checkpoint control in cdc2-3w mutants}

Mutations in the fission yeast wee1 gene advance mitosis but do not abolish the dependence of mitosis on DNA replication (Enoch and Nurse 1990), suggesting that the wee1 gene product is not required for checkpoint control. Lundgren et al. (1991) have since described a second mitotic inhibitory kinase that functions in conjunction with weel. The absence of both weel and mikl is apparently lethal because cells are undergoing premature lethal mitosis. Although strains lacking the mik1 gene arrest normally in $\mathrm{HU}$, mik1 wee $1^{\text {ts }}$ double mutants enter mitosis as soon as cells are shifted to restrictive conditions, even when DNA synthesis is blocked (Lundgren et al. 1991). These experiments suggest that there are circumstances in which weel is important for checkpoint control.

To investigate further the role of wee1 in checkpoint control, we asked whether overexpression of wee1 can restore checkpoint control in cdc2-3w cells. Overexpres-
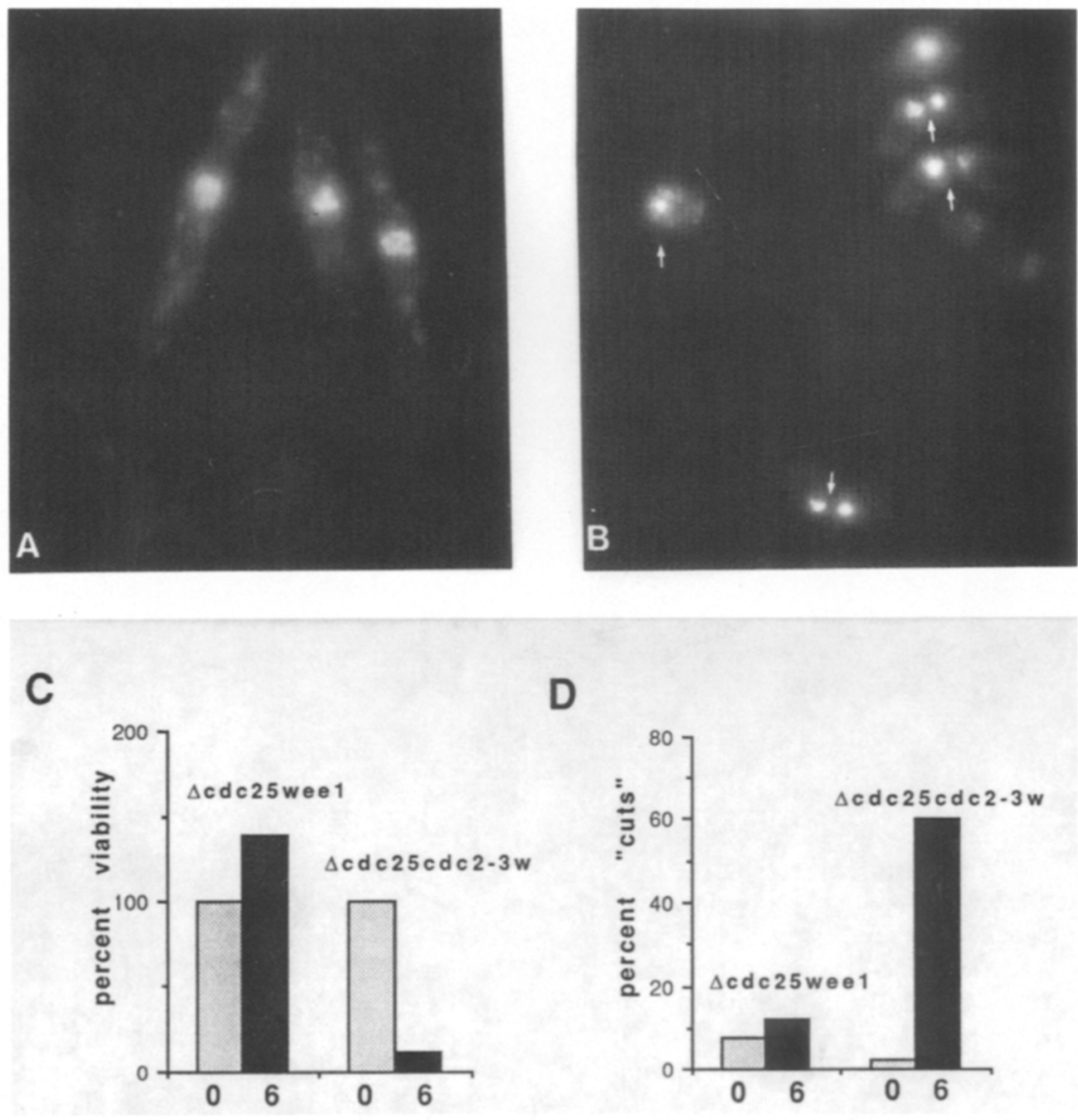

Figure 6. Coupling of mitosis to the completion of DNA replication can occur in the absence of $c d c 25$ and wee1. Strains $\Delta c d c 25$ wee1-50 /which lacks the entire $c d c 25$ gene and has a temperature-sensitive mutation in wee1) and $\Delta c d c 25 c d c 2$ $3 w$ (Russell and Nurse 1986; Enoch et al. 1992) were incubated at $36.5^{\circ} \mathrm{C}$ in $\mathrm{HU}$ for 6 hr. After $6 \mathrm{hr}$ in HU, $\Delta c d c 25$ wee $1-50$ cells were elongated and unseptated $(A)$, which is characteristic of normal cell cycle arrest in HU. In contrast, $\Delta c d c 25 c d c 2-3 w$ failed to arrest, as judged by cut formation and the presence of cells with abnormally small amounts of nuclear material $\langle B ; a b$ normal cells and cuts are indicated by arrows). Samples were fixed and stained with DAPI as in Fig. 1. The number of cut cells was counted in each culture $(D$, shaded bars, percent cuts before HU addition; solid bars, percent cuts after $6 \mathrm{hr}$ in HU). A low, constant level of cuts that was unaffected by $\mathrm{HU}$ treatment was observed for $\Delta c d c 25$ wee1-50, whereas HU incubation resulted in high levels of cut formation in $\Delta c d c 25 c d c 2-3 w$. Viability measurements $(C)$ showed that $\Delta c d c 25$ wee1 50 cells remain viable and $\Delta c d c 25 c d c 2$ $3 w$ cells lose viability /shaded bars, percent viability at $0 \mathrm{hr}$; solid bars, percent viability after $8 \mathrm{hr}$ in $\mathrm{HU}$ ). 
sion of wee1 blocks cell division in wild type cells, but this phenotype is partially suppressed by the $c d c 2-3 \mathrm{w}$ mutation, although the length of $\mathrm{G}_{2}$ is significantly extended in these cells (Russell and Nurse 1987). To investigate whether this can restore checkpoint control, we transformed $c d c 2-3 w$ cells with pREPWEEl, a plasmid containing the wee1 gene under the control of a thiamine-repressible promoter (Maundrell 1990).
As shown in Fig. 7, when wee1 expression is induced by incubation in thiamine-free media, transformants can arrest normally in $\mathrm{HU}$, as judged by the fact that they remain viable (Fig. 7D) and do not form cuts (Fig. 7E). Moreover these cells display the characteristic elongated $c d c$ phenotype in $\mathrm{HU}$ (Fig. 7, cf. B with A and C).

In this experiment, the expression of wee1 was not rescuing HU-treated cells simply by blocking cell divi-
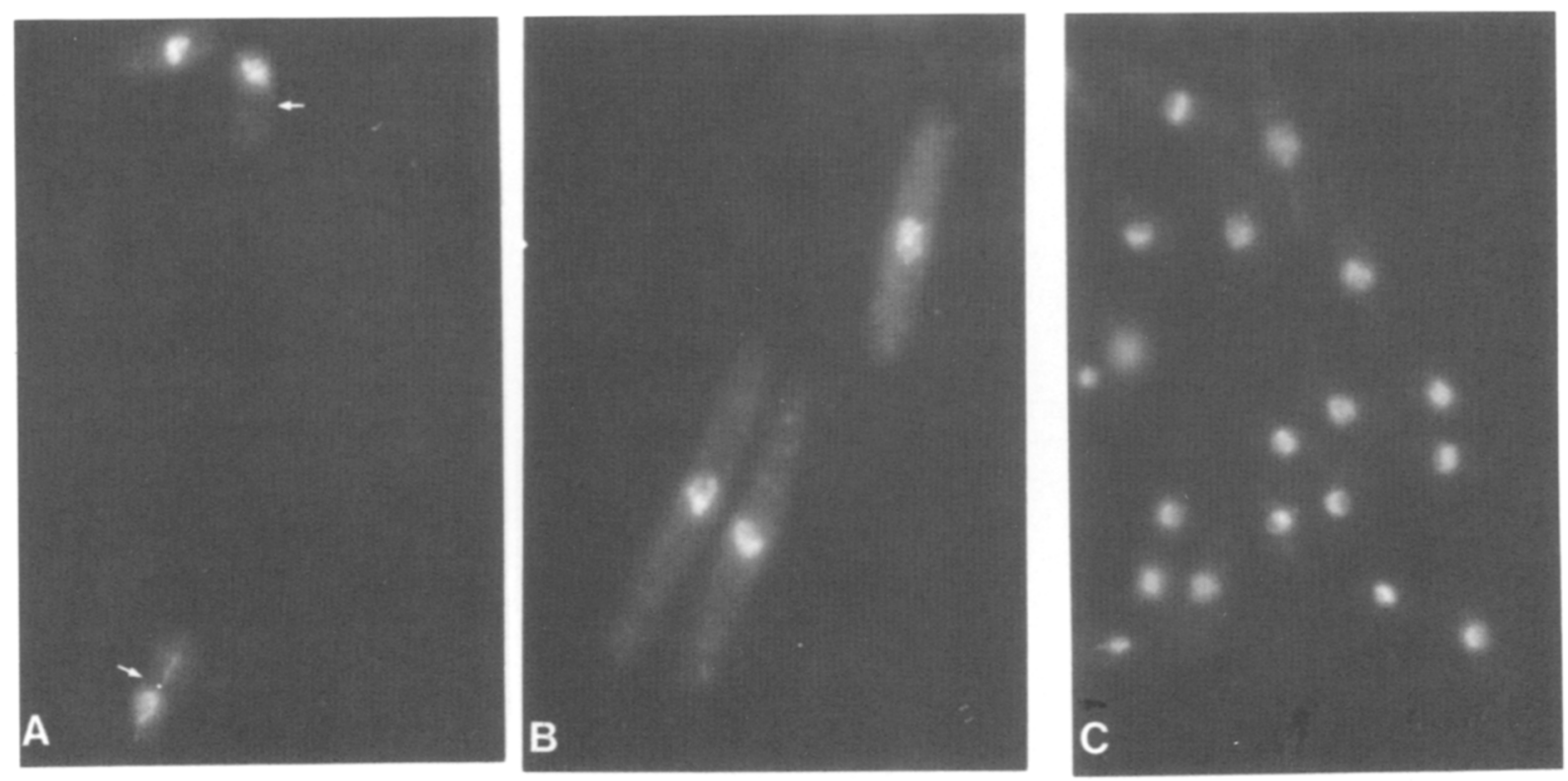

D

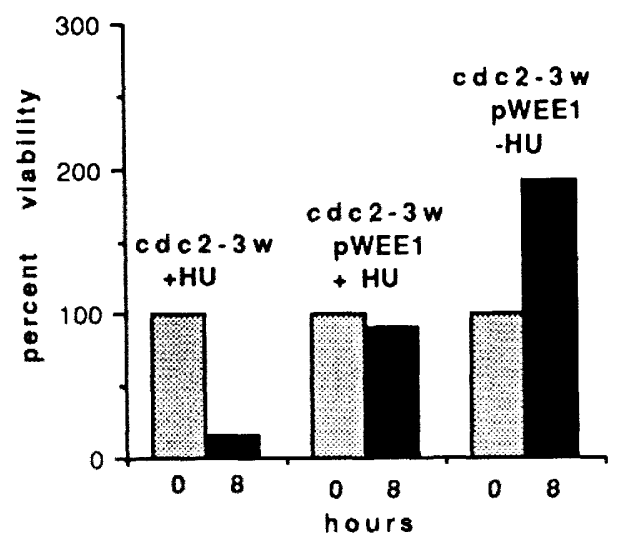

$\mathbf{E}$

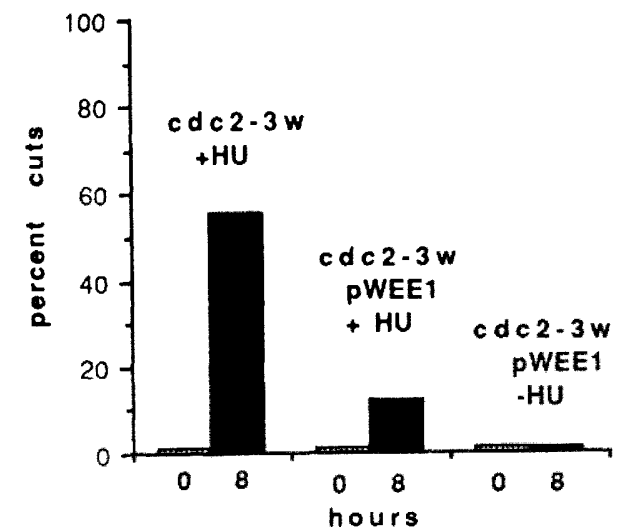

Figure 7. Overexpression of wee1 restores the coupling of mitosis to the completion of DNA replication in $c d c 2-3 w$ cells. $c d c 2-3 w$ cells were transformed with the plasmid pREPWEEl (for details, see Materials and methods). In this plasmid wee1 expression is controlled by the nmt-1 promoter, which is thiamine repressible (Maundrell 1990). These transformants (designated $c d c 2-3 \mathrm{~W}$ pWEE1 and $c d c 2-3 w$ cells transformed with the vector pREPl (designated $c d c 2-3 w$ ) were incubated in thiamine-free media in the presence or absence of $\mathrm{HU}$ for $8 \mathrm{hr}$. Although $c d c 2-3 w$ cells transformed with the plasmid displayed the characteristic cut morphology $(A$; arrows indicate septa), $c d c 2-3 w$ pWEEl cells underwent cell cycle arrest as judged by the fact that they elongated and did not septate $(B)$. Untreated $c d c 2-3 w$ pWEE 1 cells continued to divide normally $(C)$. Cells were fixed and stained with DAPI as in Fig. 1 . Viability $(D)$ and cut formation $(E)$ were also monitored in each culture. Stippled bars indicate measurements made at the start of the experiment; solid bars are measurements made after $8 \mathrm{hr}$ in $\mathrm{HU}$. As expected $c d c 2-3 \mathrm{w}$ cells transformed with the control plasmid lost viability and formed cuts. In contrast, cells transformed with pWEE1 remain viable and formed only low levels of cuts (this low level may have been the result of plasmid loss). Untreated $c d c 2-3 w$ pWEE1 divided normally, as judged by the increase in viability and lack of cuts. 
sion, because the cells divided normally in the absence of $\mathrm{HU}$, judging by morphology (Fig. $7 \mathrm{C}$ ) and the increase in viable cells during the course of the experiment (Fig. 7D). Thus, weel can clearly influence checkpoint control under certain circumstances, although the checkpoint can operate in its absence (Enoch and Nurse 1990).

\section{Discussion}

\section{Identification of fission yeast genes involved in coupling mitosis to completion of DNA replication}

We have developed a screen for mutants that enter mitosis when DNA replication is inhibited by HU and have used this screen to identify eight genes involved in coupling mitosis to the completion of DNA replication. The collection of mutants contains five new genes, hus1hus5, and alleles of three previously identified fission yeast rad genes, rad1, rad3, and rad17. The budding yeast $R A D 9$ gene has been shown to be required for radiation-induced cell cycle arrest (Weinert and Hartwell 1988). Recent studies have demonstrated that rad1 (AlKhodairy and Carr 1992; Rowley et al. 1992/a, rad3, rad9, and rad17 (Al-Khodairy and Carr 1992) play an analogous role in fission yeast. Although the Saccharomyces cerevisiae $R A D 9$ gene is required for radiationinduced cell cycle arrest, it is not required for arrest in $\mathrm{HU}$ (Hartwell and Weinert 1989). In contrast, the fission yeast rad1, rad3, rad9, and rad17 mutants also enter mitosis when cells are arrested early in S phase by treatment with HU /Al-Khodairy and Carr 1992; Rowley et al. 1992a). Thus, in fission yeast, mechanisms coupling mitosis to the completion of DNA replication and repair of radiation-induced DNA damage involve many of the same elements. For this reason our screen for HU-sensitive mutants identified rad genes. The five hus mutants are also radiation sensitive (Fig. 3), suggesting that they may also be required for radiation-induced cell cycle delay. The screen is unlikely to be saturated, as we identified only one allele for several of the genes (Table 1) and we did not isolate rad9 or $c d c 2-3 w$ mutants.

Unlike the $c d c 2-3 w$ mutation, mutation of the hus and rad genes abolishes the $G_{2} / M$ checkpoint without advancing the cell cycle. Moreover, unlike the $c d c 2-3 w$ mutation, the hus and rad mutations do not suppress the lack of $c d c 25$ function or wee1 overexpression. However, as with $c d c 2-3 w$, all of these checkpoint-deficient mutations are lethal when combined with deficiencies in the mitotic inhibitor wee1, and the double mutants display features characteristic of lethal premature entry into mitosis (Fig. 2; see also Al-Khodairy and Carr 1992; Rowley et al. 1992). This shows that the hus and rad gene products are not only required when the cell cycle is blocked by inhibitors of DNA replication or radiation. It is possible that they are not required during a normal cell cycle because $G_{1}$ and $S$ phase take up only $20 \%$ of the wild type fission yeast cell cycle, allowing sufficient time for the completion of DNA replication before the initiation of mitosis even when the checkpoint coupling the two events has been abolished by mutation. However, in wee1 mutants, $\mathrm{G}_{2}$ is much shorter, and a functional checkpoint could become absolutely required to ensure that mitosis is not initiated before DNA replication is complete.

The hus/rad mutants are sensitive to radiation, whereas $c d c 2-3 w$ is no more sensitive than wild type. In addition, mutations in the wee1 gene increase sensitivity to radiation (Al-Khodairy and Carr 1992; Rowley et al. 1992b). On the basis of these data, it has been suggested that $c d c 2-3 w$ is only deficient in the checkpoint that monitors DNA replication and not in the checkpoint that monitors radiation-induced damage, which is proposed to require wee1 (Al-Khodairy and Carr 1992; Rowley et al. 1992b). This is puzzling, given that all of the hus and rad genes identified in our screen for HU sensitivity affect both checkpoints, and the products of these genes are likely to act upstream of the mitotic control elements. It may be misleading to assess checkpoint control using only viability measurements in this case, as hus and rad mutants appear to have an additional deficiency (see below) that may contribute more significantly to their radiation sensitivity than the checkpoint deficiency. To determine conclusively that cdc2-3w cells lack a $\mathrm{G}_{2}$ radiation checkpoint will require irradiating cells synchronized in $\mathrm{G}_{2}$, an experiment that is difficult to do for technical reasons (Al-Khodairy and Carr 1992).

\section{Early-cut mutants are deficient in an additional function required to survive inhibition of DNA replication}

We have categorized the mutants that we have isolated as early-cut, late cut, and constant cut, based on the kinetics of cut formation when cells are treated with $\mathrm{HU}$ (Table 2). Studies using synchronized cultures have established that $c d c 2-3 w$ is completely deficient in checkpoint control; cells incubated in $\mathrm{HU}$ enter mitosis at the same time as untreated cultures (Fig. 5; Enoch and Nurse 1990). The five early-cut mutants, hus1, hus2, rad1, rad3, and rad17 form cuts with the same kinetics as $c d c 2-3 w$ in asynchronous cultures and are thus likely to be quantitatively as deficient in checkpoint control ( Table 2; Fig. 4). However, the early-cut mutants are much less viable than $c d c 2-3 \mathrm{~W}$ after treatment with $\mathrm{HU}$ (Table 2 ; Fig. 4A). Analysis of synchronous cultures of hus1-14 reveals that the cells become irreversibly damaged by $\mathrm{HU}$ as cells arrest in S phase (Fig. 5B), in contrast to $c d c 2-3 w$ cells, which lose the ability to recover from $\mathrm{HU}$ treatment only as they undergo division (Fig. 5A). Moreover, although the same proportion of cells enters mitosis in each culture, $\sim 20 \%$ of the $c d c 2-3 w$ cells survive, possibly because the septum misses the nucleus. In contrast, even these cells die in the hus1-14 strain.

The dramatic loss of viability of the hus and rad mutants in HU suggests that recovery from S-phase arrest entails more than resumption of the interrupted cell cycle, as gene products (i.e., the hus and rad proteins) that are not required during normal cell cycle progression become essential under these circumstances. Some possi- 
ble functions for the hus and rad proteins might be maintaining the replication complex at the replication fork during S-phase arrest, preserving the structure of the replication bubble, repairing damage caused by a poorly functioning polymerase, or controlling expression of genes involved in any of these processes. The radiation sensitivity of these mutants suggests that these functions are also required for recovery from DNA damage.

As the hus and rad mutations also uncouple mitotic events from the completion of DNA replication, the checkpoint monitoring completion of DNA replication must be intimately related to recovery from S-phase arrest. The hus and rad gene products could be required to generate an intracellular signal that activates S-phase recovery functions as well as inhibiting mitosis. Alternatively, the recovery structures that include hus and rad proteins could be the primary intracellular signal detected by the mitotic checkpoint control proteins. Although this is contrary to a view of checkpoint proteins as being extrinsic to the processes they monitor (Weinert and Hartwell 1988), the Escherichia coli SOS system provides a precedent for this type of control. The RecA protein in this system has both a repair role, being essential for recombination, and a signaling role as it activates gene expression by proteolysis of repressors (for review, see Walker 1984).

The primary function of the hus and rad early-cut genes remains to be determined. Molecular analysis of the husl and hus 2 genes is currently in progress. The rad1 (Sunnerhagen et al. 1990), rad9 (Murray et al. 1991), rad17 (A. Carr, in prep.), and rad3 genes (Seaton et al. 1992) have been cloned and sequenced, and the sequences reveal no similarity with any other proteins in the available data bases, including the product of the budding yeast $R A D 9$ gene. Thus, linking DNA synthesis and repair to mitotic control appears to involve novel processes. The understanding of these processes may have practical implications, as agents that inhibit DNA synthesis are frequently used in cancer chemotherapy.

\section{How is unreplicated DNA detected by cdc2?}

During $S$ phase and $G_{2}$, cdc2 is phosphorylated on a tyrosine residue in the ATP-binding site by the kinases weel and mik1. At mitosis, cdc2 is dephosphorylated by the product of the $c d c 25$ gene, and this results in activation of the kinase. Tyrosine phosphorylation of cdc2 is also required for the monitoring of DNA replication (Dasso and Newport 1990; Enoch et al. 1991), and overexpression of cdc25 reduces tyrosine phosphorylation and can abolish the dependence of mitosis on the completion of DNA replication (Enoch and Nurse 1990; Kumagai and Dunphy 1991). In contrast, cells lacking wee1 arrest normally in HU. On the basis of these data, we have previously proposed that $c d c 25$ activity is dependent on the completion of DNA replication and that weel functions to monitor other types of signals.

However, as we have shown here (Fig. 6), HU can inhibit mitosis in the absence of $c d c 25$ and wee1. In addition, we find that the overexpression of wee 1 restores the checkpoint in $c d c 2-3 w$ cells, which would otherwise be deficient (Fig. 7). This is probably not an indirect consequence of the increased length of $G_{2}$ in these strains, as $\mathrm{G}_{2}$ is also likely to be extended in the checkpoint-deficient $\Delta c d c 25 c d c 2-3 w$ strain (Fig. 6; see Russell and Nurse 1987). Taken together, these data suggest that both weel and cdc25 can influence checkpoint control under certain circumstances but that neither one can be the only link between primary checkpoint signals and control of cdc2 activity.

It is possible that redundant pathways couple mitosis to the completion of DNA replication. Inhibition of DNA replication could increase cdc2 tyrosine phosphorylation both by inhibiting the activity of the phosphatase cdc25 and by enhancing the activity of the kinases weel and mik1 (Lundgren et al. 1991). Evidence supporting each of these mechanisms has been obtained using Xenopus cell-free systems (Kumagai and Dunphy 1991; Smythe and Newport 1992).

Alternatively, the cdc25, weel, and mik1 proteins could be playing indirect roles in the checkpoint control. Unreplicated DNA could activate an inhibitor that is only capable of interacting with the tyrosine-phosphorylated form of cdc2. If this were the case, the relative amount of tyrosine-phosphorylated cdc2 would be predicted to play a crucial role in determining the responsiveness of the cell cycle to checkpoint signals. Therefore, mutations in mik1, wee1, or cdc25 that result in reduced levels of cdc2 tyrosine phosphorylation could be acting by decreasing sensitivity to checkpoint signals rather than interfering directly with transmission of the checkpoint signal.

Studying the effects of inhibition of DNA replication on weel, mikl, cdc25, and cdc2 might be one way to distinguish between these models. The hus/rad mutants will be valuable tools for such studies, as DNA replication can be inhibited in these strains without generating a checkpoint signal.

\section{Checkpoint control in fission yeast-an intracellular signal transduction pathway}

The coupling of mitosis to the completion of DNA replication requires signal transduction pathways, although the signals and the receiving elements are all intracellular. Mutations in at least 12 different genes can disrupt this pathway in fission yeast (Enoch and Nurse 1990; Lundgren et al. 1991; Al-Khodairy and Carr 1992; Rowley et al. 1992a), and these fall into two general categories (Fig. 8). The first class consists of mutations in cell cycle control proteins that also advance the cell cycle. We propose that in these mutants, the receiving element (cdc2) is rendered insensitive to the signal (completion of replication). The second category consists of mutations in hus1, hus2, rad1, rad3, rad9, and rad17 genes that also have a deficiency in recovery from S-phase arrest and radiation. In contrast to the first category, these mutations do not advance the cell cycle. We propose that these mutants are unable to generate or transmit the intracellular signal that inhibits cdc2 when DNA is dam- 


\section{DNA Replication Blocked}

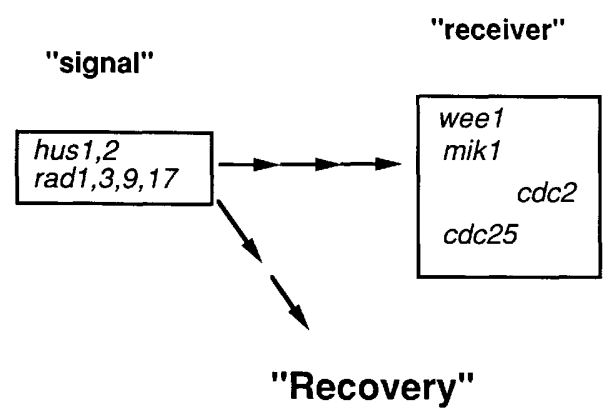

Figure 8. Model for intracellular signal transduction pathway that couples mitosis to the completion of DNA replication. Mutations in the indicated fission yeast genes can uncouple mitosis from the completion of DNA replication (for references, see text). Some of these mutations are in cell cycle control elements, which we propose abolish the ability of cdc2 to "receive" the information that DNA replication is blocked. In contrast, the hus and rad gene products are required to "signal" mitotic control proteins when DNA replication is blocked. These genes may also be required for recovery from S-phase arrest and DNA damage.

aged or replication is incomplete. Three other genes identified here, hus3, hus4, and hus5 may be involved as well. The number of genes involved suggests that coupling mitosis to the completion of DNA replication requires a complex and interesting signal transduction pathway.

\section{Materials and Methods}

\section{Media and chemicals}

All media and stocks were prepared as described in Moreno et al. (1991). Minimal medium is EMM (Moreno et al. 1991) (0.5\% glucose supplemented, unless otherwise noted, with adenine, uracil, leucine, histidine, and lysine). HU (Sigma) was prepared as a $200 \mathrm{~mm}$ stock in distilled water and filter sterilized.

\section{Genetics methods}

To isolate hus mutants, strain PN567 (derived from 972h-; genotype ade6-704 ura4-D18 leu1-32 $h$-) was mutagenized with nitrosoguanidine to $30 \%$ viability using standard procedures (Moreno et al. 1991). After mutagenesis, cells were plated on $\mathrm{YE} /$ agar plates at a density of $\sim 500$ colonies per plate. After 3 days of growth at $29^{\circ} \mathrm{C}$, cells were replica plated to $\mathrm{PB}$ (yeast extract $+5 \mu \mathrm{g} / \mathrm{ml}$ of phloxin B) plates and PB-HU plates (yeast extract $+2.5 \mu \mathrm{g} / \mathrm{ml}$ of phloxin $\mathrm{B}+10 \mathrm{~mm} \mathrm{HU}$. Colony growth on PB and PB-HU plates was initially compared macroscopically, and colonies that grew poorly on $\mathrm{PB}-\mathrm{HU}$ were patched on YE plates and retested. Potential positives were then grown to an $\mathrm{OD}_{595}$ of $0.1-0.5$ in EMM, HU was added to a concentration of $10 \mathrm{mM}$, and after 8-12 hr cells were fixed and stained with DAPI as described previously (Enoch and Nurse 1990). Linkage was determined by performing random spore analysis on pairwise crosses of the mutants and scoring for recombinants. All the hus mutants, as well as representative alleles of the rad genes (rad1-h24, rad3-h15, rad17-h11), were back-crossed five times. To investigate linkage with cell cycle control genes, the hus mutants were crossed to $c d c 2-33$, cdc25, wee1-50, rad1.1, rad3.136, rad9.192 and rad17.W and the number of recombinants was determined using similar methods.

\section{Physiology methods}

Unless otherwise noted, physiological experiments were performed in EMM at $29^{\circ} \mathrm{C}$ as preliminary experiments suggest that cutting in many of these mutants is suppressed at higher temperatures, although the cells still lose viability under these conditions (data not shown). To arrest cells with HU, cultures were grown to an $\mathrm{OD}_{595}$ of $0.1-0.2$ in minimal media. At this point, HU was added to a final concentration of $10 \mathrm{~mm}$. To monitor viability, $10 \mu \mathrm{l}$ aliquots of the cultures were removed, diluted into $10 \mathrm{ml}$ of distilled water, and sonicated briefly. One hundred microliters of this mixture was plated on YE plates, and colonies were counted after 3-4 days growth at $29^{\circ} \mathrm{C}$. To monitor cut formation, cells were fixed and stained with DAPI as described previously (Enoch and Nurse 1990) or fixed and stained with DAPI and $100 \mu \mathrm{g} / \mathrm{ml}$ of calcofluor. As shown in Figure 1, septa can be detected as bright lines after calcofluor + DAPI staining or as dark lines in cells stained only with DAPI. We routinely used only DAPI, because nuclear the structure can be seen more clearly. To determine the percentage of cells in $G_{1}$, cells were fixed and analyzed using a BecktonDickinson FACSCAN as described by Sazer and Sherwood (1990). Radiation survival experiments were carried out as described previously (Al-Khodairy and Carr 1992).

In the experiments described in Figure 7, cells were grown overnight in EMM medium containing $50 \mu \mathrm{g} / \mathrm{ml}$ thiamine, and then reinoculated into thiamine-free EMM medium at low density. Cells were grown for $15 \mathrm{hr}$ to an OD of $0.1-0.2$ and $\mathrm{HU}$ was then added where appropriate to a concentration of $10 \mathrm{~mm}$.

\section{Strain and plasmid constructions}

Construction of strains $\Delta c d c 25$ wee1-50, and $\Delta c d c 25 c d c 2-3 w$, which lack the entire $c d c 25$-coding region, has been described. Many of the $\Delta c d c 25$ wee1-50 spores failed to germinate, and those that did might survive because they carry a suppressor (Enoch et al. 1991). The plasmid pREPWEE1 was the generous gift of Dr. Sergio Moreno, (Oxford University). It was constructed by performing polymerase chain reaction (PCR) on the plasmid pwee1.1 (Russell and Nurse 1987), using the oligonucleotides GAGAACAGGATCCTCTAAAAG and CCACAGGATCCATACAGAAAC as primers. The PCR products were digested with BamHI and then cloned into BamHI-digested pREP1, which contains the promoter of the nmt-1 gene, which is thiamine repressible, as well as the fission yeast leu2 gene and an ars sequence (Maundrell 1990). This plasmid was introduced into $c d c 2-3 w$ cells, and $\mathrm{leu}^{+}$transformants were selected on minimal media plates containing $50 \mu \mathrm{g} / \mathrm{ml}$ of thiamine. Transformants were first replica plated to plates lacking thiamine to derepress the $n m t-1$ promoter. Colonies on the plate lacking thiamine were then replica-plated again to two sets of plates lacking thiamine, one of which contained $10 \mathrm{~mm}$ HU. In $\sim 50 \%$ of the colonies, cell division was blocked both in the presence and absence of $\mathrm{HU}$. In the remaining transformants, cells arrested in $\mathrm{HU}$, but division took place normally in the absence of HU. These transformants were picked and analyzed in liquid culture as described above. The differences between transformants probably reflect differences in the copy number of the transformed plasmid. 


\section{Acknowledgments}

We thank Fahd Al-Khodairy for assistance with linkage analysis, Sergio Moreno for the gift of the plasmid pREPWEEl, Chris Norbury, Juan Jiménez, Karim Labib, and Tom Kelly for comments on the manuscript, and members of the Nurse laboratory for numerous helpful discussions. Work in our laboratories is supported by the ICRF and the MRC.

The publication costs of this article were defrayed in part by payment of page charges. This article must therefore be hereby marked "advertisement" in accordance with 18 USC section 1734 solely to indicate this fact.

\section{References}

Al-Khodairy, F. and A.M. Carr. 1992. DNA repair mutants defining $\mathrm{G}_{2}$ checkpoint pathways in Schizosaccharomyces pombe. EMBO \%. 11: 1343-1350.

Amon, A., U. Surana, I. Muroff, and K. Nasmyth. 1992. Regulation of $\mathrm{p} 34^{\mathrm{CDC} 28}$ tyrosine phosphorylation is not required for entry into mitosis in S. cerevisiae. Nature 355: 368-371.

Byers, B. 1981. Cytology of the yeast life cycle. In The molecular biology of the yeast Saccharomyces: Life cycle and inheritance (ed. J.N. Strathern, E.W. Jones, and J.R. Broach). pp. 59-96. Cold Spring Harbor Laboratory, Cold Spring Harbor, New York.

Dasso, M. and J.W. Newport. 1990. Completion of DNA replication is monitored by a feedback system that controls the initiation of mitosis in vitro: Studies in Xenopus. Cell 61: 811-825.

Enoch, T. and P. Nurse. 1990. Mutation of fission yeast cell cycle control genes abolishes dependence of mitosis on DNA replication. Cell 60: 665-673.

- 1991. Coupling M phase and S phase: Controls maintaining the dependence of mitosis on chromosome replication. Cell 65: 921-923.

Enoch, T., K. Gould, and P. Nurse. 1991. Mitotic checkpoint control in fission yeast. Cold Spring Harbor Symp. Quant. Biol. 56: 409-417.

Fantes, P. 1979. Epistatic gene interaction in the control of division in the fission yeast. Nature 279: 428-430.

-1981. Isolation of cell size mutants of a fission yeast by a new selective method: Characterization of mutants and implications for division control mechanisms. J. Bacteriol. 146: 746-754.

Featherstone, C. and P. Russell. 1991. Fission yeast p107 ${ }^{\text {weel }}$ is a tyrosine/serine kinase. Nature 349: 808-811.

Forsburg, S. and P. Nurse. 1991. Cell cycle regulation in the yeasts Saccharomyces cerevisiae and Schizosaccharomyces pombe. Annu. Rev. Cell Biol. 7: 227-256.

Gould, K. and P. Nurse. 1989. Tyrosine phosphorylation of the fission yeast $\mathrm{Cdc2}^{+}$protein kinase regulates entry into mitosis. Nature 342: 39-45.

Hartwell, L. and T. Weinert. 1989. Checkpoints: Controls that ensure the order of cell cycle events. Science 246: 629-634.

Hirano, T., S. Funahashi, T. Uemura, and M. Yanagida. 1986. Isolation and characterization of Schizosaccharomyces pombe cut mutants that block nuclear division but not cytokinesis. EMBO I. 5: 2973-2979.

Hoyt, M.A., L. Totis, and B.T. Roberts. 1991. S. cerevisiae genes required for cell cycle arrest in response to loss of microtubule function. Cell 66: 507-517.

Krek, W. and E.A. Nigg. 1991. Differential phosphorylation of vertebrate $p 34 c d c 2$ kinase at the G1/S and G2/M transitions in the cell cycle: Identification of major phosphorylation sites. EMBO J. 10: 305-317.

Kumagai, A. and W.G. Dunphy. 1991. The cdc25 protein controls tyrosine dephosphorylation of the cdc2 protein in a cell free system. Cell 64: 903-914.
Li, R. and A.W. Murray. 1991. Feedback control of mitosis in budding yeast. Cell 66: 519-531.

Lundgren, K., N. Walworth, R. Booher, M. Dembski, M. Kirschner, and D. Beach. 1991. mikl and weel cooperate in the inhibitory tyrosine phosphorylation of cdc2. Cell 64: $1111-$ 1122.

Maller, J.L. 1990. Mitotic control. Curr. Opin. Cell Biol. 3: 269275.

Maundrell, K. 1990. nmt1 of fission yeast. I. Biol. Chem. 265: $10857-10864$.

Millar, J. and P. Russell. 1992. The cdc25 M-phase inducer: An unconventional protein phosphatase. Cell 68: 407-410.

Moreno, S., A. Klar, and P. Nurse. 1991 Molecular genetic analysis of fission yeast Schizosaccharomyces pombe. In Methods in enzymology: Guide to yeast genetics and molecular biology (ed. C. Guthrie and G.R. Fink), vol. 94, pp. 795-823. Academic Press, New York.

Murray, A.M. and M. Kirschner. 1989. Dominoes and clocks: The union of two views of cell cycle regulation. Science 246: 614-621.

Murray, J.M., A.M. Carr, A.R. Lehmann, and F.Z. Watts. 1991. Cloning and characterization of the rad9 DNA repair gene from Schizosaccharomyces pombe. Nucleic Acids Res. 19: 3525-3531.

Nurse, P. 1975. Genetic control of cell size at cell division in yeast. Nature 256: 547-551.

.1990. Universal control mechanism regulating the onset of M-phase. Nature 344: 503-508.

Phipps, J., A. Nasim, and D.R. Miller. 1985. Recovery, repair and mutagenesis in Schizosaccharomyces pombe. Adv. Genet. 23: $1-55$.

Rowley, R., S. Subramani, and P. G. Young. 1992a. Checkpoint controls in Schizosaccharomyces pombe: rad1. EMBO I. 11: 1335-1342.

Rowley, R., J. Hudson, and P.G. Young. 1992b. The wee1 protein kinase is required for radiation-induced mitotic delay. Nature 356: 353-355.

Russell, P. and P. Nurse. 1986. $c d c 25^{+}$functions as a mitotic inducer in the mitotic control of fission yeast. Cell 45: 145153.

- 1987. Negative regulation of mitosis by wee $1^{+}$, a gene encoding a protein kinase homolog. Cell 49: 559-567.

Sazer, S. and S.W. Sherwood. 1990. Mitochondrial growth and DNA synthesis occur in the absence of nuclear DNA replication in fission yeast. J. Cell Sci. 97: 509-516.

Seaton, B. L., J. Yucel, P. Sunnerhagen, and S. Subramani. 1992. Isolation and characterization of the Schizosaccharomyces pombe gene, involved in the DNA damage and DNA synthesis check points. Gene (in press).

Smythe, C. and J.W. Newport. 1992. Coupling of mitosis to the completion of $S$ phase in Xenopus occurs via modulation of the tyrosine kinase that phosphorylates p34cdc2. Cell 68: $787-797$.

Sorger, P.K. and A.W. Murray. 1992. S phase feedback control in budding yeast independent of tyrosine phosphorylation of p34 ${ }^{\mathrm{CDC} 28}$. Nature 355: 365-367.

Sunnerhagen, P., B. Seaton, A. Nasim, and S. Subranami. 1990. Cloning and analysis of a gene involved in DNA repair and recombination, the rad1 gene of Schizosaccharomyces pombe. Mol. Cell Biol. 10: 3750-3760.

Walker, G.C. 1984. Mutagenesis and inducible responses to deoxyribnucleic acid damage in Escherichia coli. Microbiol. Rev. 48: 60-93.

Weinert, T.A. and L.H. Hartwell. 1988. The RAD9 gene controls the cell cycle response to DNA damage in Saccharomyces cerevisiae. Science 241: 317-322. 


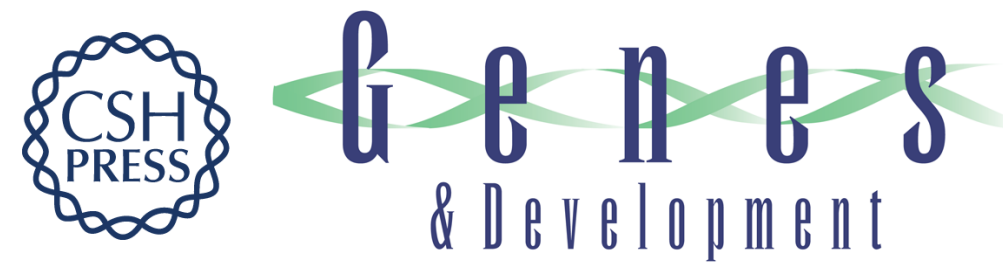

\title{
Fission yeast genes involved in coupling mitosis to completion of DNA replication.
}

\author{
T Enoch, A M Carr and P Nurse
}

Genes Dev. 1992, 6:

Access the most recent version at doi:10.1101/gad.6.11.2035

References

This article cites 36 articles, 9 of which can be accessed free at: http://genesdev.cshlp.org/content/6/11/2035.full.html\#ref-list-1

\section{License}

Email Alerting

Receive free email alerts when new articles cite this article - sign up in the box at the top Service right corner of the article or click here.

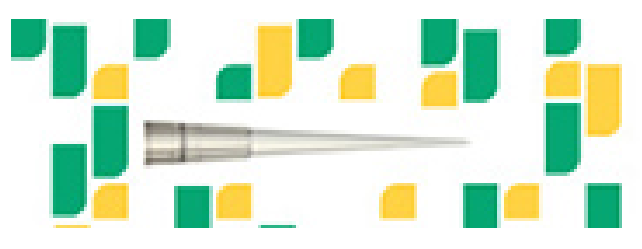

Focused on your science. 